\title{
UNSTEADY RATE OF ATP HYDROLYSIS BY MYOSIN AND ACTOMYOSIN IN ITS INITIAL PHASE
}

\author{
KOKI UCHIDA* \\ Department of Physiology, Sapporo Medical College
}

Quantitative studies on the enzymatic property of actomyosin have been carried out by Mommaerts $(1,2)$ Morales et al. $(3,4)$ and Tonomura et al. $(5$, 6). However, in all of these reports, the time course of ATP hydrolysis by ATPase was supposed to follow the process like that of a general enzymatic reaction. Weber and Hasselbach (7) have reported the phenomenon that the rate of ATP hydrolysis in the initial phase is greater than that in the later phase and that the former is at least twice as high as the rate in the steady state. They have concluded that the high value of hydrolysis is not due to the fact that the start of hydrolysis causes contraction of the relaxed fibrils. Also the present author observed the same phenomenon when attempted to measure the ATPase activity of myosin B in order to obtain Michaelis constant in the condition without any effectors. $\dagger$

It is not yet clarified how this phenomenon correlates with the mechanism of muscular contraction or the changes of the property of actomyosin molecule. However, this phenomenon seems to be very interesting from the view point of enzyme chemistry. In the present work, this high initial rate of ATP hydrolysis by $\mathrm{H}$-meromyosin, myosin and myosin $\mathrm{B}$ was observed in detail.

\section{MATERIALS AND METHOD}

"Crystalline" myosin was prepared according to A. Szent-Györgyi (8) and actin according to Straub (9). The synthetic actomyosin was made up of 2 $\mathrm{mg}$. myosin and $0.7 \mathrm{mg}$. actin per $3 \mathrm{ml}$. of total reaction mixture. Myosin $\mathrm{B}$ was prepared from rabbit muscle by extraction for $24 \mathrm{hrs}$. in Weber's solution and purified by three successive precipitations and dissolutions. H-meromyosin was prepared from crystalline myosin as described by A. G. Szent-Györgyi (10). Protein nitrogen was determined by micro-Kjeldahl analysis.

ATP-Ba salt was prepared in this laboratory, it was converted into neutral $\mathrm{K}$ salt solution for use. Further purification was made by separating with

Received for publication December 13, 1957.

* 内田竍喜

The following abbreviations are used: ITP for inosine triphosphate, GTP for guanosine triphosphate, UTP for uridine triphosphate, ATPase for adenosine triphosphatase, Tris buffer for tris-(hydroxymethyl)-aminomethane $\mathrm{HCl}$ buffer, and EDTA for ethylenediamineteraacetic acid.

+ This was presented by K. Konishi (one of members of this laboratory) at the 2nd meeting of the Symposium on Biophysics and Biophysical Chemistry (Nagoya Feb. 1956). 
Amberlite IRA-401. One-third of fraction which was eluted with $0.2 \mathrm{~N} \mathrm{NaCl}$ $0.01 \mathrm{~N} \mathrm{HCl}$ solution, was used as ATP solution. ITP was prepared from ATP according to Kleinzeller (11).

Pyrophosphate was recrystallized from commercial product and was used as $0.1 \mathrm{M}$ stock solution which was regulated to $p_{\mathrm{H}} 7.0$ with $1 \mathrm{~N} \mathrm{HCl}$.

ATPase activity was measured by the following procedure: The reaction mixture was made up by adding $0.5 \mathrm{ml}$. of ATP solution in the test tube which contained $3 \mathrm{M} \mathrm{KCl}$ or $0.3 \mathrm{M} \mathrm{KCl}$ solution to make the final concentrations $0.6 \mathrm{M}$ or $0.1 \mathrm{M}, 1 \mathrm{ml}$. of $0.1 \mathrm{M}$ Tris buffer $(p \mathrm{H} 7.0)$, the stock solutions of $\mathrm{CaCl}_{2}$, of $\mathrm{MgCl}_{2}$ and of pyrophosphate to make the final concentrations as shown in figures, $2 \mathrm{mg}$. of enzyme and water to make the total volume $3.0 \mathrm{ml}$. One incubated the mixture, except for the ATP, for 7 minutes in a constant temperature bath at $20^{\circ} \mathrm{C}$. in order to assure the proper temperature. The enzyme action was started by the addition of $0.5 \mathrm{ml}$. of ATP solution, previously adjusted to the temperature. After a measured time, the action was stopped by the addition of $2 \mathrm{ml}$. of $5 \%$ trichloracetic acid. The tube was shaken before and after the addition of ATP. It took 2 to $2.5 \mathrm{sec}$. to introduce ATP or trichloracetic acid to the systems. The blank was made up by adding trichloracetic acid before the addition of ATP. The precipitated protein was eliminated by the filtration through a dry filter paper. Phosphorus concentrations were measured colorimetrically, using the Fiske and Subbarow method.

The determination of ATP and ADP was made according to Cohn and Carter (12). The concentrations of ATP and ADP in each fraction were determined from the extinction at $260 \mathrm{~m} \mu$ by means of a Shimazu spectrophotometer QB 50. In this case, the enzyme action was stopped by adding $2 \mathrm{ml}$. of $10 \%$ perchloric acid.

RESULTS

The author followed the time course of ATP hydrolysis by myosin B in which physical changes were caused by ATP at $0.6 \mathrm{M}$, as well as, that of ATP hydrolysis by myosin and $\mathrm{H}$-meromyosin in which no such physical changes were resulted by ATP. In all cases, the rate of hydrolysis was great and liable to variation in the initial phase and it fell gradually to become steady in about one minute (fig. 1).

The rates of ITP, UTP and GTP hydrolyses are greater than the rate of ATP hydrolysis (13). ATP samples may possibly contain some other nucleotides as impurities, resulting in an increase of the rate of hydrolysis. For excluding this possibity, the ATP sample which had been purified twice by ion exchange resin was used as substrate. Even in this case, the unsteady rate of ATP hydrolysis in the initial phase was also observed. Furthermore, the following experiment was made in order to exclude the above possibility: Three $\mathrm{ml}$. of a mixture of $3 \times 10^{-3} \mathrm{M} \mathrm{ATP}, 1.8 \mathrm{mg}$. of myosin and $0.4 \mathrm{M} \mathrm{KCl}$ either before incubation, or after incubation at $20^{\circ} \mathrm{C}$. for one and two minutes respectively, was quickly diluted by addition of 4 volumes of cold $0.03 \mathrm{~m}$ Tris buffer. The myosin was centrifuged out. After the incubation for 2 min., the unsteady state was over, but the ATP concentration was still capable of saturation. The super- 


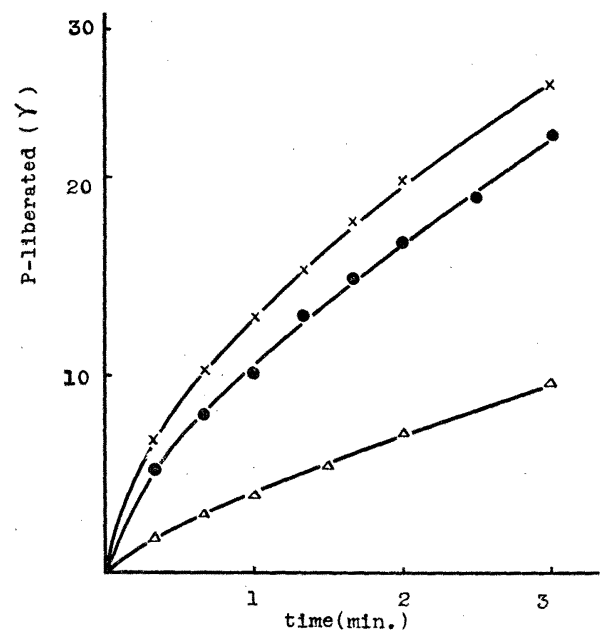

FIG. 1. Hydrolysis of ATP by ATPases. $p \mathrm{H}: 7.0, \mathrm{ATP}: 5 \times 10^{-4} \mathrm{M}, \mathrm{KCl}: 0.6 \mathrm{M}$, temp.: $20^{\circ} \mathrm{C}$.

$\triangle-\Delta 0.7 \mathrm{mg} / \mathrm{ml}$. of myosin $\mathrm{B}$.

$0.7 \mathrm{mg} / \mathrm{ml}$. of myosin.

$x-\times 0.5 \mathrm{mg} / \mathrm{ml}$. of H-meromyosin.

phosphate production. The amounts of ATP split and of ADP produced within 30 seconds, one minute and 3 minutes respectively after the begin. ning of the reaction were analyzed by using the ion exchanger and, at the same time, orthophosphate liberated was measured according to Fiske and Subbarow method. H-meromyosin was used as ATPase. The uncorrectness of this assumption was evidenced by the results illustrated in fig. 2 .

Examinations were made to determine whether or not the change in the rate of ATP hydrolysis is effected by the presence of $\mathrm{Ca}^{++}$, $\mathrm{Mg}^{++}$and pyrophosphate. As shown in fig. 3, the presence of $10^{-5} \mathrm{M} \mathrm{Mg}^{++}$ shortened the time needed to get into the steady state. The presence of $5 \times 10^{-4} \mathrm{M} \mathrm{Ca}^{++}$and $5 \times 10^{-3} \mathrm{M}$ pyrophosphate elongated this time. In the presence of both $10^{-5} \mathrm{M} \mathrm{Mg}^{++}$ natants were incubated with second portion of myosin at $0.4 \mathrm{M} \mathrm{KCl}$. All supernatants used as substrates showed the same result, i.e. the rate of ATP hydrolysis was unsteady in the initial phase. This phenomenon was not affected by using $5 \times 10^{-4} \mathrm{M}$ ATP which contained a small amount of ITP $\left(10^{-5} \mathrm{M}, 5 \times 10^{-5} \mathrm{M}\right.$ and $10^{-4} \mathrm{M}$ respectively).

If this phenomenon is due to the fact that orthophosphates bound to myosin are rapidly liberated in the initial phase by the addition of ATP so that these phosphates are added to the phosphates liberated from ATP, the rate of $\mathrm{ADP}$ production cannot be parallel with the rate of ortho-

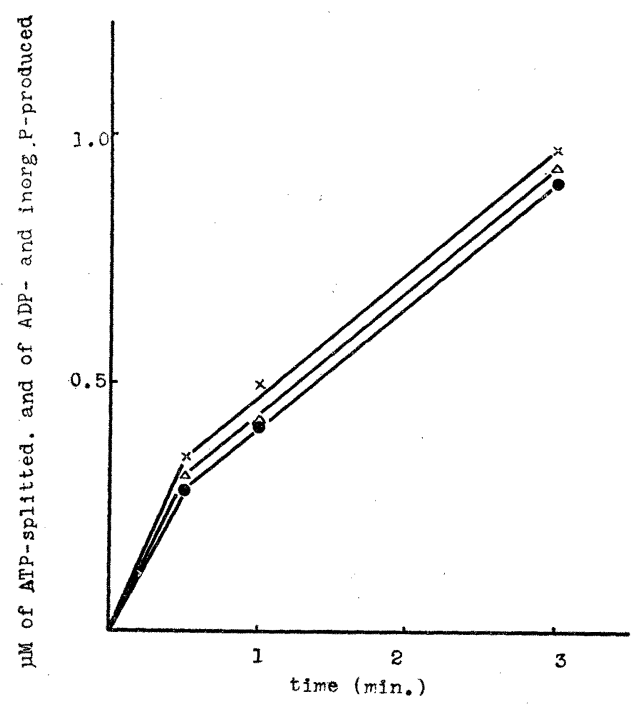

FIG. 2. Analysis of ATP, ADP and inorg. $P$ in reaction mixture.

ATP and ADP were determined by Cohn and Carter's method, and inorg. $P$ determined by Fiske and Subbarow method. H-meromyosin was used as ATPase.

Original concentration of ATP: $5 \times 10^{-4} \mathrm{M}$

$p \mathrm{H}: 7.0, \mathrm{KCl} 0.6 \mathrm{M}$, temp.: $20^{\circ} \mathrm{C}$.

$\times-x$ ATP-splitted.

$\triangle \longrightarrow$ ADP-produced.

- inorganic P. 


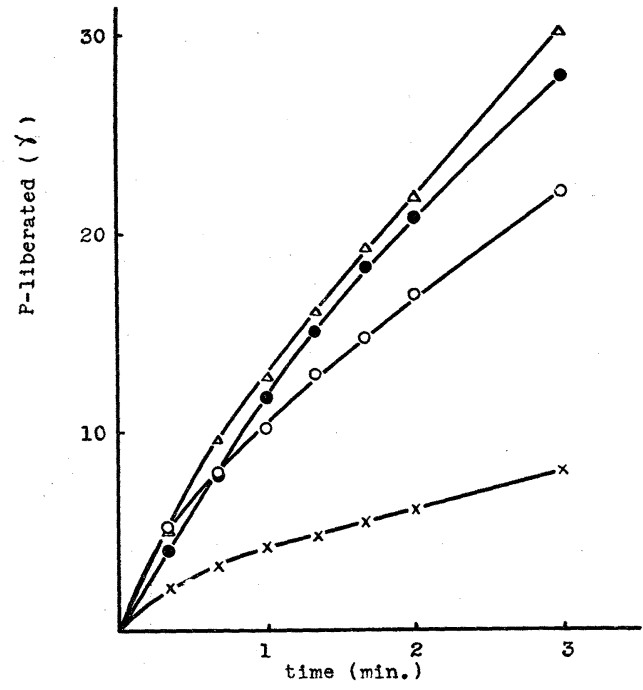

FIG. 3. The effects of $\mathrm{Ca}, \mathrm{Mg}$ and pyrophosphate on the time course of ATP hydrolysis by myosin.

pH: 7.0, myosin: $0.7 \mathrm{mg} / \mathrm{ml} .$, ATP:
$5 \times 10^{-4} \mathrm{M}, \mathrm{KCl}: 0.6 \mathrm{M}$, temp.: $20^{\circ} \mathrm{C}$.
$\circ-\mathrm{KCl}$ alone
$\times-\times 10^{-5} \mathrm{M} \mathrm{MgCl}_{2}$
$\triangle-\triangle 5 \times 10^{-4} \mathrm{M} \mathrm{CaCl}_{2}$
$\square-\square \times 10^{-3} \mathrm{M}$ pyrophosphate

FIG. 5. ATP hydrolysis by myosin in various concentrations of ATP.

Purified ATP was used, conditions were the same in above experiment.

Concentration of ATP:

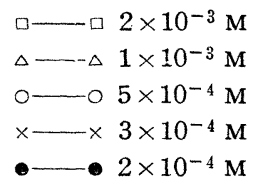

and $10^{-3} \mathrm{M} \mathrm{Ca}^{++}$, the time that the rate of ATP hydrolysis is unsteady, was similar to that in the absence of $\mathrm{Mg}^{++}$ and $\mathrm{Ca}^{++}$(fig. 4).

The effect of changes in concent-

ration of the substrate on this phenomenon was observed (fig. 5). It seemed that the time needed to get into the steady state was not strikingly affected by the change of substrate concentration,

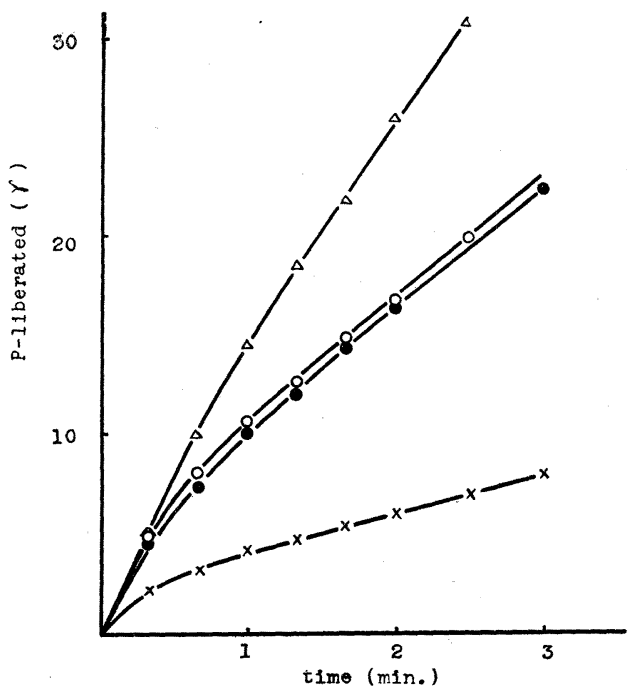

FIG. 4. The effects of $\mathrm{Ca}$ and $\mathrm{Mg}$ on the rate of ATP hydrolysis by myosin.

pH: 7.0 , myosin: $0.7 \mathrm{mg} / \mathrm{ml}$., ATP:

$5 \times 10^{-4} \mathrm{M}, \mathrm{KCl}: 0.6 \mathrm{M}$, temp.: $20^{\circ} \mathrm{C}$.

$\mathrm{O}-\mathrm{KCl}$ alone

$\times \longrightarrow \times 10^{-5} \mathrm{M} \mathrm{MgCl}_{2}$

$\triangle \longrightarrow 10^{-3} \mathrm{M} \mathrm{CaCl}_{2}$

- $10^{-3} \mathrm{M} \mathrm{CaCl}_{2}+10^{-5} \mathrm{M} \mathrm{MgCl}_{2}$

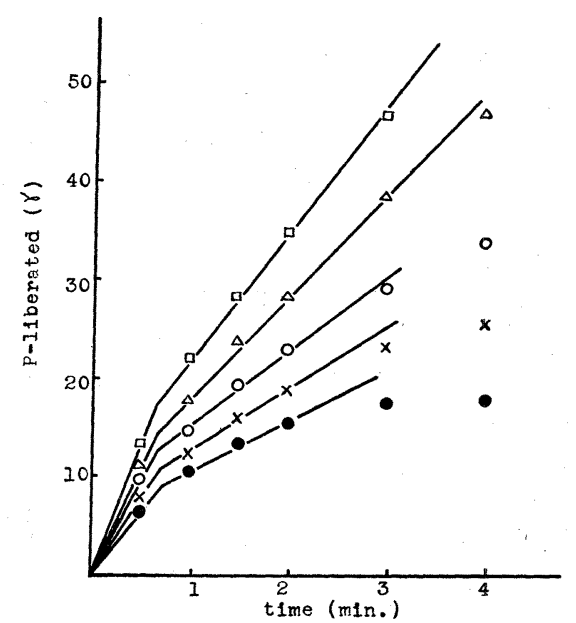


A plot of some linear relationship between reaction rate and substrate concentration was commonly used to estimate the constants of myosin and actomyosin in the initial step and in the steady state. It was recognized that the apparent Michaelis constant in the initial step was different from the constant in the steady state (table 1 ).

\section{DISCUSSION}

It was ascertained that the rate of ATP hydrolysis by $\mathrm{H}$-meromyosin, myosin, actomyosin and myosin $\mathrm{B}^{*}$ was not steady at the beginning of enzyme action. This phenomenon was not due to the fact that the rate of formation of an enzyme-substrate complex was small. If the rate of the complex formation be the cause of this phenomenon, the initial rate would be smaller than that of the steady state.

The results that the unsteadiness of the rate in initial phase was observed with myosin and $\mathrm{H}$-meromyosin, may suggest that this phenomenon is not due to the physical deformation of protein molecule. From the same reason, it may be known that this phenomenon did not connect directly with the contraction of muscle fiber and superprecipitation of actomyosin. This explanation is in agreement with the conclusion of A. Weber and W. Hasselbach (7).

It is not easy to remove other nucleosidetriphosphates in the ATP sample by using the Cohn and Carter method. However, two facts that the ATP solution treated once by myosin still showed the unsteady state when incubated with a second portion of myosin and that the addition of a small amount of ITP did not affect the time elapsed before the onset of the steady state, may strongly support the consideration that this phenomenon is not due to these impurities in the ATP sample.

Miyazaki et al. (14) observed also the same phenomenon in the case of inorganic triphosphate hydrolysis by myosin. It may indicate that this phenomenon is not due to ATP. Further, they estimated the amount of phosphorus liberated by using the Youngburg-Youngburg method. Then this penomenon is not due to the method of phosphorus determination. Chiuma (15) observed the same phenomenon on the measurement of the rate of ATP hydrolysis by water soluble ATPase in brain homogenate.

The result as shown in fig. 2 suggests that all phosphates liberated are originated from the end group of ATP. Accordingly, it seems that the change of the rate in initial phase is due to the change of enzymatic property of myosin itself.

On the basis of the results in fig. 3 and fig. 4 , it seems certain that the time required for bringing about the steady state is greatly regulated by the presence of bivalent metal ions. Spicer (16) has reported that pyrophosphate forms a complex with bivalent metal. $\mathrm{Mg}^{++}$appears to form a complex more readily than $\mathrm{Ca}^{++}$does. The elongation of the time for the onset of the steady state by the presence of pyrophosphate may be due to the removal of $\mathrm{Mg}^{++}$

* Recently, Dr. Y. Tonomura and Mr. S. Kitagawa have investigated this phenomenon by means of their excellent apparatus (personal communication), 
which shortens the time.* At $0.1 \mathrm{M} \mathrm{KCl}$, the ATPase activity of actomyosin was decreased by the addition of $5 \times 10^{-3} \mathrm{M}$ pyrophosphate, but the rate of ATP hydrolysis was steady.

Accordingly, it may be suggested that the change of enzymatic property of myosin is induced by the interaction between ATP and $\mathrm{Mg}^{++}$bound to myosin during the unsteady state of ATP hydrolysis.

TABLE 1. Michaelis-Menten Constants of Myosin and Actomyosin in the Initial Step (I) and Stationary Step (II)

\begin{tabular}{|c|c|c|c|c|c|c|c|c|}
\hline \multirow{2}{*}{ Effector } & \multirow[b]{2}{*}{$\mathrm{Km}$} & \multirow[b]{2}{*}{$\mathrm{Vm}$} & \multicolumn{2}{|c|}{$\begin{array}{c}\mathrm{Ca} \\
5 \times 10^{-4} \mathrm{M}\end{array}$} & \multicolumn{2}{|c|}{$\underset{10^{-5} \mathrm{Mg}}{\mathrm{Mg}}$} & \multicolumn{2}{|c|}{$\begin{array}{c}\text { Pyrophosphate } \\
5 \times 10^{-3} \mathrm{M}\end{array}$} \\
\hline & & & $\mathrm{Km}$ & $\mathrm{Vm}$ & $\mathrm{Km}$ & $\mathrm{Vm}$ & $\mathrm{Km}$ & $\mathrm{Vm}$ \\
\hline Myosin $(0.6 \mathrm{M} \mathrm{K})$ & $\begin{array}{l}2.7 \\
5.5\end{array}$ & $\begin{array}{r}12.9 \\
6.2\end{array}$ & $\begin{array}{l}1.3 \\
5.0\end{array}$ & $\begin{array}{l}9.0 \\
8.7\end{array}$ & $\begin{array}{l}6.2 \\
5.2\end{array}$ & $\begin{array}{l}6.6 \\
1.7\end{array}$ & $\begin{array}{r}3.3 \\
10.0\end{array}$ & $\begin{array}{l}11.3 \\
11.4\end{array}$ \\
\hline $\begin{array}{l}\text { Actomyosin } \\
(0.6 \mathrm{M} \mathrm{K})\end{array}$ & $\begin{array}{l}4.5 \\
4.1\end{array}$ & $\begin{array}{l}7.0 \\
3.0\end{array}$ & $\begin{array}{l}1.5 \\
4.1\end{array}$ & $\begin{array}{l}6.8 \\
5.4\end{array}$ & $\begin{array}{l}10.0 \\
11.7\end{array}$ & $\begin{array}{l}4.7 \\
1.5\end{array}$ & $\begin{array}{l}4.5 \\
9.0\end{array}$ & $\begin{array}{l}10.7 \\
11.6\end{array}$ \\
\hline $\begin{array}{l}\text { Actomyosin } \\
(0.1 \mathrm{M} \mathrm{K})\end{array}$ & $\begin{array}{l}1.5 \\
6.0\end{array}$ & $\begin{array}{l}7.5 \\
5.2\end{array}$ & & & $\begin{array}{l}2.2 \\
4.0\end{array}$ & $\begin{array}{l}8.1 \\
6.0\end{array}$ & 6.2 & 2.3 \\
\hline
\end{tabular}

$\mathrm{Km}: \times 10^{-4} \mathrm{M}, \mathrm{Vm}: \gamma \mathrm{P} / \mathrm{min} / \mathrm{mg}$. of myosin.

It is not exact to calculate the rate of the initial phase from the amount of phosphorus liberated within $30 \mathrm{sec}$. after the beginning of the reaction. The value obtained is a tentative one. It seems more natural that the true initial rate is more greater. Morever, the values in initial step shown in table 1 are the apparent constant because the steady state of the reaction does not take place yet.

The unsteady rate of ATP hydrolysis in the initial phase, or the change of enzymatic property of myosin, may arise from the interaction between ATP and myosin which is mediated by $\mathrm{Mg}^{++}$. The change of enzymatic property can not arise from the removal of $\mathrm{Mg}^{++}$in the presence of pyrophosphate (or EDTA). And $\mathrm{Ca}^{++}$which is antagonistic to $\mathrm{Mg}^{++}$, makes this phenomenon difficult to arise.

\section{SUMMARY}

1. The time course of ATP hydrolysis by myosin, H-meromyosin, myosin B and synthetic actomyosin was followed. The rate of ATP hydrolysis in the initial phase was unsteady, and was grater than that of ATP hydrolysis in the steady state.

2. This phenomenon was due to neither to the impurity in ATP sample, nor to the rapid liberation of orthophosphate bound to myosin by the addition of ATP.

3. The time needed to get into the steady state was shortened by the

\footnotetext{
* The rate of ATP hydrolysis in the initial phase was steady in the presence of $10^{-3}$ M EDTA,
} 
addition of $\mathrm{Mg}^{++}$and was elongated by the addition of $\mathrm{Ca}^{++}$, of pyrophosphate and of EDTA.

4. The magnitude of Michaelis constant in the initial phase was different from that of Michaelis constant in the steady state.

5. The cause of this phenomenon was discussed.

\section{ACKNOWLEDGEMENT}

The author is much indebted to Prof. T. Nagai and Prof. E. Miyazaki of our laboratory for their guidance and support, and to Mr. K. Konishi, Mr. H. Takahashi and Dr. Makinose for their advice.

This study was aided by a grant-in-aid for Fundamental Scientific Research of the Ministry of Education.

\section{REFERENCES}

1. Mommaerts, W. F. H. M. J. Gen. Physiol. 30: 201, 1948.

2. Mommaerts, W. F. H. M. AND Green, I. J. Biol. Chem. 208: 833, 1954.

3. Ouellet, L., Laidler, K. J. And Morales, M. F. Arch. Biochem. and Biophys. 39: 37, 1952.

4. Blum, J. J. ANd Morales, M. F. Arch. Biochem. and Biophys. 43: 208, 1953.

5. TONOMURA, Y. ET AL. J. Biochem. (Tokyo) 40: 27, 1953.

6. Tonomura, Y. eT AL. J. Biochem. (Tokyo) 40: 387, 1953.

7. Weber, A. And Hasselbach, W. Biochim. et Biophys. Acta 15: 237, 1954.

8. SZEnT-Györgyi, A. Stud. Szeged. 3: 76, 1943.

9. Straub, S. B. Stud. Szeged. 3: 23, 1943.

10. Szent-Györgyi, A. G. Arch. Biochem. and Biophys. 42: 305, 1953.

11. KLEINZEller, A. Biochem. J. 36: 729, 1942.

12. Cohn, W. E. And Carter, C. E. J. Am. Chem. Soc. 72: 4273, 1950.

13. Kielley, W. W., Kalckar, H. M. And Bradley, L. B. J. Biol. Chem. 219: 95, 1956.

14. TAKAHASHI, M. AND MIYAZAKI, E. Journal of the Faculty of Science, Hokkaido University, Series VI, 31: 308, 1957.

15. CHIUMA, I. personal communication.

16. Spicer, S. S. J. Biol. Chem. 199: 289, 1952. 